\title{
PENGUJIAN MESIN KOMPOSTER KOMUNAL SAMPAH RUMAH TANGGA TIPE ROTARY HORIZONTAL KAPASITAS 40 KG
}

\author{
Noviyanti Nugraha ${ }^{3}$, Moh. Azis $\mathrm{M}^{2}$, Odi Fauzi ${ }^{3}$, Irvan Ulum ${ }^{4}$ \\ ${ }^{1,2,4}$ Jurusan Teknik Mesin, Fakultas Teknologi Industri, Institut Teknologi Nasional \\ Jl. P.H.H. Mustofa No. 23. Bandung, 40124. \\ ${ }^{3}$ P4TK Bidang Mesin dan Teknik Industri \\ Jl Pesantren km 2 Cibabat, Cimahi \\ Email : noviyanti.nugraha.itenas@gmail.com,
}

\begin{abstract}
Abstrak
Sampah rumah tangga diantaranya sampah sisa sayuran merupakan sampah organik yang dapat didaur ulang atau diolah kembali. Salah satu upaya pengolahan sampah organik yaitu dengan cara mengolahnya menjadi pupuk kompos. Untuk mempercepat proses pengomposan dibutuhkan komposter. Pada penelitian sebelumnya telah dirancang dan dibuat sebuah mesin komposter komunal rumah tangga tipe rotary berkapasitas $40 \mathrm{~kg}$ sampah. Tujuan dari penelitian ini adalah melakukan pengujian terhadap komposter komunal tipe rotary horizontal berkapasitas $40 \mathrm{~kg}$ hasil pengembangan yang sudah dilakukan pada penelitian sebelumnya. Pengujian dilakukan pada putaran drum $18 \mathrm{rpm}, 25 \mathrm{rpm}$ dan $30 \mathrm{rpm}$, dengan memutar komposter setiap hari dilakukan sampai kompos matang. Parameter yang diuji adalah lamanya waktu pengomposan, temperatur, $\mathrm{pH}$, kadar air, kandungan karbon dan nitrogen. Target proses pengomposan adalah 14 hari atau 2 minggu. Hasil pengujian diperoleh waktu pengomposan sesuai target yaitu 14, 12 dan 11 hari, temperatur maksimum pada fase thermophilik adalah $70{ }^{\circ} \mathrm{C}$, PH maks 7, kandungan karbon maks 33\%, kandungan nitrogen maks 1,2\%, rasio C/N maks 32,6, kadar air maks 35,3\%, kadungan kompos yang dihasilkan untuk rasio C/N diatas standar SNI 2004 sebesar 3\%, sedangkan hasil lainnya rata-rata sesuai dengan standar SNI.
\end{abstract}

Kata kunci : Komposter, Sampah, Organik, Kompos

\begin{abstract}
Household waste, which is vegetable waste, is organic waste that can be recycled or reprocessed. One effort to process organic waste is by processing it into compost. To speed up the composting process, a composter is needed. In previous studies, a rotary type communal household composter machine with a capacity of $40 \mathrm{~kg}$ of waste was designed and made. The purpose of this study was to test the $40 \mathrm{~kg}$ horizontal type communal composter with the results of the development carried out in previous studies. Experiments were carried out at the drum rotation 18 rpm, $25 \mathrm{rpm}$ and $30 \mathrm{rpm}$, by turning the composter every day one playback until the compost was ready. The parameters are the length of composting time, temperature, $\mathrm{pH}$, water content, carbon and nitrogen content. The target of the composting process is 14 days or 2 weeks. The results obtained by composting time are 14, 12 and 11 days, the maximum temperature in the thermophilic phase is $70^{\circ} \mathrm{C}$, max $\mathrm{PH} 7$, max carbon content $33 \%$, max nitrogen content $1.2 \%$, max $C / N$ ratio 32.6 , moisture content max $35.3 \%$, the compost content produced for the $C / N$ ratio above the 2004 SNI standard is 3\%, while the other results are in average according to the SNI standard.
\end{abstract}

Keywords: Composter, Waste, Organic, Compost

\section{PENDAHULUAN}

Definisi sampah rumah tangga berdasarkan UU-18/2008 adalah sampah yang dihasilkan dari kegiatan sehari-hari dalam rumah tangga [Damanhuri, 2010]. Sampah rumah tangga diantara nya sampah sisa sayuran merupakan sampah organik yang dapat didaur ulang atau diolah kembali. Daur ulang adalah upaya membuat produk yang sama maupun menyerupai dengan menggunakan materi yang sama [Taqim, 2007].

8 Nugraha, Noviyanti, dkk; Pengujian Mesin Komposter Komunal Sampah Rumah Tangga Tipe Rotary Horizontal Kapasitas $40 \mathrm{Kg}$ 
Salah satu upaya pengolahan sampah organik yaitu dengan cara mengolahnya menjadi pupuk kompos. Pada dasarnya bahan baku kompos dapat diperoleh dari semua bahan organik yang ada di alam seperti Dedaunan, limbah pertanian, sampah organik rumah tangga, kotoran hewan, dll. [Tahir, 2008]

Prinsip pengomposan adalah untuk menurunkan rasio $\mathrm{C} / \mathrm{N}$ bahan organik, sehingga sama dengan rasio $\mathrm{C} / \mathrm{N}$ tanah yaitu kurang dari 20 . Semakin tinggi rasio $\mathrm{C} / \mathrm{N}$ bahan organik maka proses pengomposan semakin lama. Rasio $\mathrm{C} / \mathrm{N}$ untuk sayuran atau daun-daunan berkisar antara 4080. Untuk sayuran atau dedaunan yang ditimbun di dalam tanah, lama pembusukan sekitar 5 hingga 8 minggu [Setyorini, 2006].

Pengolahan sampah organik di Indonesia yang biasa dilakukan di daerah pedesaan, yaitu pengolahan sampah mandiri disetiap rumah dengan membuat lubang pada sebidang tanah. Pengolahan sampah dengan cara membuang sampah ke lubang tersebut dan dibiarkan membusuk seiring dengan waktu. Kelemahan dari cara ini apabila diterapkan di daerah kota adalah biaya pembuatan lubang tanah yang relatif mahal dan pemandangan sampah yang tidak enak dilihat, serta kompos yang dihasilkan memakan waktu yang cukup lama. Untuk mengatasi permasalah tersebut dibutuhkan komposter dalam pengolahan sampah organik sisa rumah tangga [Nugraha, 2017].

Pada penelitian sebelumnya telah dirancang dan dibuat sebuah mesin komposter komunal rumah tangga tipe rotary seperti yang diperlihatkan pada gambar 1. Selain berfungsi untuk mengatasi permasalahan sampah organik rumah tangga, komposter ini juga membantu proses pengomposan menjadi lebih cepat. [Nugraha, 2017].

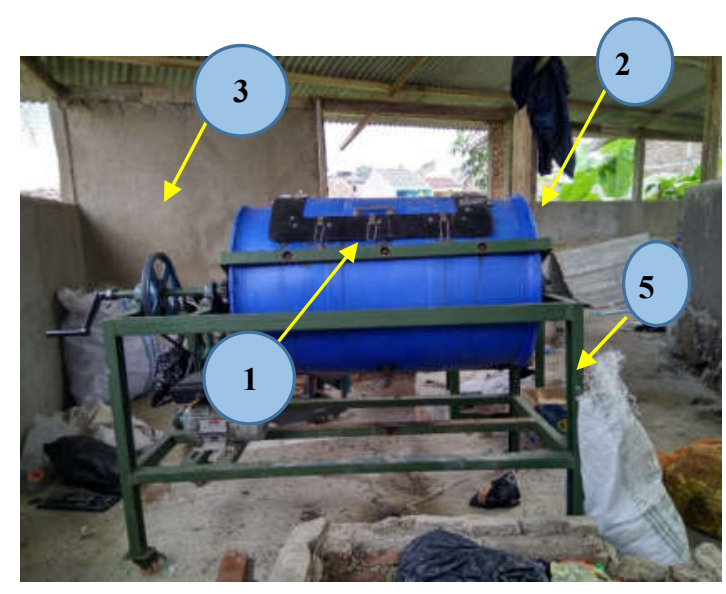

Gambar 1 Mesin komposter

Spesifikasi mesin komposter dapat dilihat pada tabel 1 .
Tabel 1 Spesifikasi Mesin Komposter

\begin{tabular}{|c|c|}
\hline \multicolumn{2}{|c|}{ SPESIFIKASI MESIN KOMPOSTER } \\
\hline Kapasitas & $40 \mathrm{~kg}$ \\
\hline Daya motor & $5,5 \mathrm{HP}$ \\
\hline $\begin{array}{l}\text { Dimensi } \\
(\mathrm{p} \times 1 \times \mathrm{t})\end{array}$ & $(1450 \times 730 \times 1028) \mathrm{mm}$ \\
\hline \multicolumn{2}{|l|}{ Drum } \\
\hline Dimensi & $\begin{array}{l}\text { Volume } 200 \text { liter } \\
\text { Diameter } 580 \\
\text { Tinggi } 920 \mathrm{~mm}\end{array}$ \\
\hline Material & Plastik \\
\hline \multicolumn{2}{|c|}{ Rangka Agitator } \\
\hline Dimensi & $\begin{array}{l}\text { Diameter } 620 \mathrm{~mm} \\
\text { Panjang } 1230 \mathrm{~mm}\end{array}$ \\
\hline Material & $\begin{array}{l}\text { Rectangular tube } \\
40 \times 20 \times 2.3 \\
\text { AISI } 1030\left(34,5 \mathrm{~kg} / \mathrm{mm}^{2}\right)\end{array}$ \\
\hline \multicolumn{2}{|l|}{ Pulley } \\
\hline \multicolumn{2}{|c|}{ Motor bensin 5,5 Hp } \\
\hline \multicolumn{2}{|c|}{ Rangka utama } \\
\hline \multicolumn{2}{|c|}{$\begin{array}{l}\text { Dimensi } \\
(p \times 1 \times t)\end{array}$} \\
\hline \multicolumn{2}{|l|}{ Agitator } \\
\hline Material & AISI $1030\left(34,5 \mathrm{~kg} / \mathrm{mm}^{2}\right)$ \\
\hline \multicolumn{2}{|c|}{ Agitator horizontal (3 buah) } \\
\hline $\begin{array}{l}\text { Dimensi } \\
(p \times 1 \times t)\end{array}$ & $(296 \times 100 \times 2) \mathrm{mm}$ \\
\hline \multicolumn{2}{|c|}{ Agitator sudut $30^{0}$ (6 buah) } \\
\hline $\begin{array}{l}\text { Dimensi } \\
\left(\begin{array}{l}p \\
\mathbf{p}\end{array} \mid \begin{array}{l}\mathbf{x} \\
\mathrm{t}\end{array}\right)\end{array}$ & $(330 \times 100 \times 2) \mathrm{mm}$ \\
\hline Material & AISI $1030\left(34,5 \mathrm{~kg} / \mathrm{mm}^{2}\right)$ \\
\hline \multicolumn{2}{|c|}{ Lubang ventilasi udara } \\
\hline Dimensi & $25 \mathrm{~mm}$ \\
\hline $\begin{array}{l}\text { Berjumlah } \\
\text { (kanan } 5 \text { da }\end{array}$ & $\begin{array}{l}\text { lbang } \\
\text { ri } 5 \text { lubang) }\end{array}$ \\
\hline
\end{tabular}

Komposter tersebut digerakan secara rotary dengan agitator di bagian dalam komposter. Agitator seperti pada gambar 2. berfungsi untuk mengaduk, mencampurkan, dan meratakan sampah dengan tujuan agar proses pengomposan dapat lebih singkat [Nugraha, 2017].

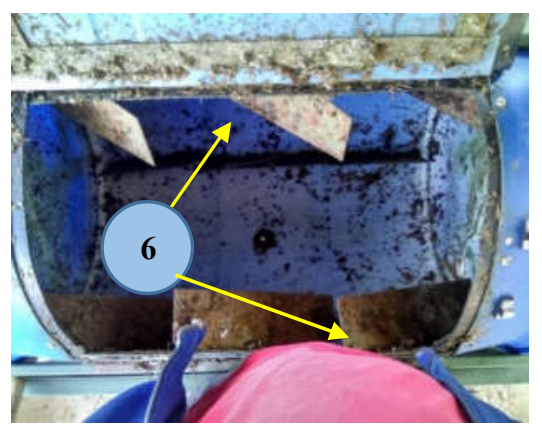

Gambar 2 Agitator (Pengaduk)

9 Nugraha, Noviyanti, dkk; Pengujian Mesin Komposter Komunal Sampah Rumah Tangga Tipe Rotary Horizontal Kapasitas $40 \mathrm{Kg}$ 


\section{Pada penelitian sebelumnya telah dilakukan pengembangan komposter,} pengembangan yang telah dilakukan diantara nya memberi lubang pada bagian samping drum untuk pemasukan udara pada saat proses pengomposan, seperti terlihat pada gambar 3. Diameter lubang adalah $25 \mathrm{~mm}$ sebanyak 10 buah. Pada bagian bawah komposter terdapat lubang untuk pembuangan air lindi dengan diameter $3 \mathrm{~cm}$. Daya komposter diubah menjadi menggunakan motor bensin berkapasitas $5,5 \mathrm{hp}$ dengan putaran maksimal motor $3700 \mathrm{rpm}$ dan putaran drum adalah $53 \mathrm{rpm}$ [Nugraha. 2017]

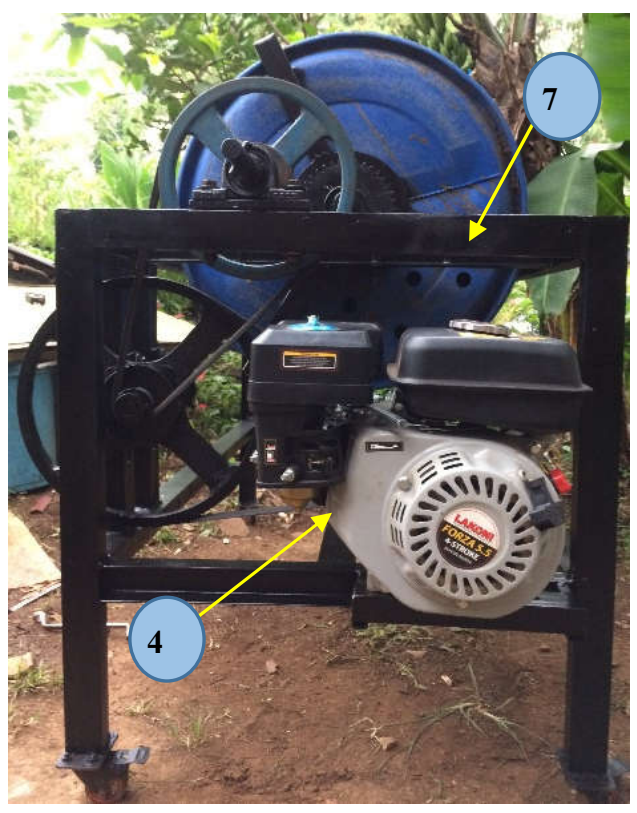

\section{Gambar 3 Komposter tampak samping}

Tujuan dari penelitian ini adalah melakukan pengujian terhadap komposter komunal tipe rotary horizontal berkapasitas $40 \mathrm{~kg}$ hasil pengembangan yang sudah dilakukan pada penelitian sebelumnya.

\section{METODE PENELITIAN}

Pengujian yang dilakukan meliputi dua jenis pengujian. Jenis pengujian pertama dilakukan untuk melihat berapa lama proses pengomposan jika menggunakan komposter. Pada pengujian ini dilakukan dua kali pengadukan atau pemutaran komposter dalam satu hari, yaitu setiap pagi dan sore, dilakukan pada putaran komposter $18 \mathrm{rpm}$, lama proses pengadukan 15 menit.

Pengujian jenis kedua dilakukan untuk melihat pengaruh putaran terhadap lamanya proses pengomposan. Pengujian ini terdiri dari dua pengujian uaitu pada putaran drum $25 \mathrm{rpm}$ dan 30 rpm. Pada pengujian ini proses pengadukan dilakukan satu kali dalam sehari, dengan masing masing pengadukan 2 menit dan 7 menit.

Target lamanya proses pengomposan adalah 14 hari atau 2 minggu. Sampah yang diuji sebanyak $40 \mathrm{~kg}$ sesuai kapasitas drum.

Prosedur pengujian adalah sebagai berikut: Sebelum dimasukan ke dalam komposter, sampah dicacah terlebih dahulu dengan ukuran $3-5 \mathrm{~cm}$, tujuan pencacahan untuk memperluas kontak antara bakteri dengan sampah. sehingga dapat mempercepat proses penguraian bakteri terhadap sampah. Setelah sampah dimasukan ke dalam drum komposter kemudian sampah diberi bakteri.

Bakteri yang diberikan adalah green phoskko berbentuk serbuk. Bakteri sebanyak 2 sendok makan dilarutkan dengan dengan 2 liter air dan 2 sendok makan gula pasir, kemudian diamkan selama 4 jam. Setelah bakteri larut, air akan berubah menjadi berwarna hitam, barulah cairan tersebut di siramkan pada sampah yang berada dalam drum komposter. Cairan bakteri dan sampah yang belum diproses diperlihatkan pada gambar 4.

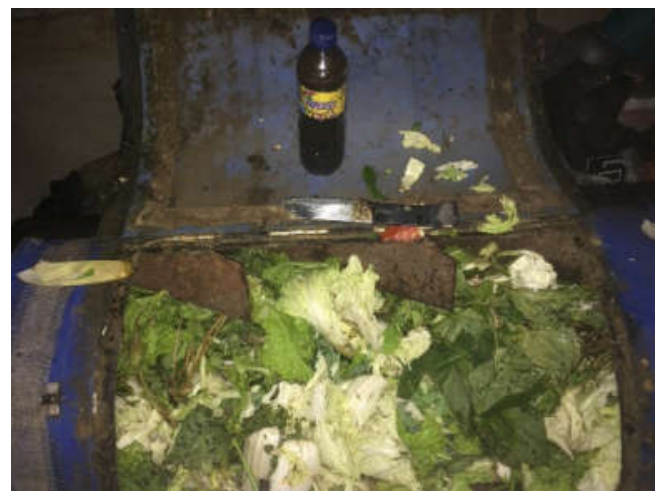

\section{Gambar 4 Sampah sebelum diproses}

Tahap selanjutnya yaitu memasang sensor thermohygrometer didalam drum lalu tutup rapat pintu dan ventilasi udara pada drum. Sensor thermohygrometer digunakan untuk mengukur temperatur dan kelembaban di dalam komposter. Tahap berikutnya adalah menyalakan motor bensin dengan putaran dan waktu pengadukan sesuai yang diinginkan, setelah pengadukan selesai matikan motor bensin.

Pada tiga hari pertama komposter ditutup secara keseluruhan sebagai pembanding temperatur dan kelembaban saat bakteri dalam keadaan belum bekerja. Fase ini dinamakan fase meshophilik. Pencatatan data pada pengamatan dilakukan setelah komposter didiamkan sekitar 60 menit dari proses pemutaran.

Data temperatur dan kelembaban dicatat setiap hari. Fermentasi atau proses penguraian pada

10 Nugraha, Noviyanti, dkk; Pengujian Mesin Komposter Komunal Sampah Rumah Tangga Tipe Rotary Horizontal Kapasitas $40 \mathrm{Kg}$ 
kompos selalu dipantau temperaturnya agar mikroorganisme pada kompos tidak mati akibat temperatur yang tinggi. Pada proses fermentasi ini air kompos dibuang agar kompos yang sedang diproses tidak tergenang air.

Pengujian dilakukan setiap hari sampai kompos matang, ciri-ciri kompos matang adalah warna kehitaman, tekstur dan bau seperti tanah. Setelah kompos telah matang maka dilakukan pengujian terhadap kompos.

Setelah kompos matang, kompos dikeluarkan dari dalam komposter dan dilakukan pengujian laboratorium untuk mengetahui kandungan kompos. Parameter yang diuji adalah temperatur, $\mathrm{pH}$, kadar air, kandungan karbon dan nitrogen. Alat yang digunakan untuk mengukur $\mathrm{PH}$ adalah PH meter sedangkan untuk memperoleh kandungan kompos dilakukan pengujian melalui laboratorium

Uji Lab dilakukan di Laboratorium pertanian Universitas Padjajaran. Metode yang digunakan untuk mengetahui unsur carbon adalah dengan metode Pengabuan Kering $660^{\circ} \mathrm{C}$, untuk mengetahui kandungan Nitrogen, dengan menggunakan alat Kjeldahl atau Titrimetry, sedangkan untuk mengukur kadar air menggunakan oven dengan temperatur $105^{\circ} \mathrm{C}$.

Pengujian jenis kedua dilakukan untuk melihat bagaimana pengaruh variasi putaran terhadap lamanya proses pengomposan. Semua proses pengujian sama dengan pengujian tahap pertama, yang membedakan adalah pada pengujian ini dilakukan dua kali yaitu pada putaran drum 25 rpm dan $30 \mathrm{rpm}$. Pada pengujian ini proses pengadukan dilakukan hanya satu kali dalam sehari.

\section{HASIL DAN PEMBAHASAN}

Pada pengujian jenis pertama data temperatur dan kelembaban untuk tiga hari pertama atau fase meshophilik dapat dilihat pada tabel 2.

Tabel 2 Data fase meshophilik

\begin{tabular}{lllll}
\hline Hari & \multicolumn{2}{l}{ Temperatur } & \multicolumn{2}{c}{ Kelembaban } \\
\cline { 2 - 5 } Ke & $\begin{array}{l}\text { Ling } \\
\left({ }^{\circ} \mathrm{C}\right)\end{array}$ & $\begin{array}{l}\text { Dlm } \\
\text { drum } \\
\left({ }^{\circ} \mathrm{C}\right)\end{array}$ & $\begin{array}{l}\text { Ling } \\
\left({ }^{\circ} \mathrm{C}\right)\end{array}$ & $\begin{array}{l}\text { Dlm } \\
\text { drum } \\
\left({ }^{\circ} \mathrm{C}\right)\end{array}$ \\
\hline 1 & 25,1 & 34,9 & 73 & 87 \\
\hline 2 & 25,4 & 35,7 & 67 & 89 \\
\hline 3 & 25,6 & 36,7 & 69 & 85 \\
\hline
\end{tabular}

Setelah didiamkan selama 3 hari tanpa pengadukan, barulah komposter diputar dengan putaran $18 \mathrm{rpm}$ dan dua kali pengadukan, diperoleh data temperatur seperti yang diperlihatkan pada tabel 3.
Tabel 3 Data pengujian putaran 18 rpm

\begin{tabular}{|c|c|c|c|}
\hline hari & $\begin{array}{l}\text { Pagi/ } \\
\text { Sore }\end{array}$ & $\begin{array}{c}\text { Temperatur } \\
\text { Rata-rata } \\
{ }^{\circ} \mathrm{C}\end{array}$ & $\begin{array}{l}\text { Kelembaban } \\
\text { Rata-rata } \\
\%\end{array}$ \\
\hline \multirow{2}{*}{1} & Pagi & 69,9 & 94 \\
\hline & Sore & 67,4 & 97 \\
\hline \multirow{2}{*}{2} & Pagi & 49,6 & 88 \\
\hline & Sore & 51,5 & 90 \\
\hline \multirow{2}{*}{3} & Pagi & 45,5 & 97 \\
\hline & Sore & 47,4 & 76 \\
\hline \multirow{2}{*}{4} & Pagi & 70 & 95 \\
\hline & Sore & 51,2 & 94 \\
\hline \multirow{2}{*}{5} & Pagi & 38,2 & 81 \\
\hline & Sore & 35,2 & 87 \\
\hline \multirow{2}{*}{6} & Pagi & 36,3 & 82 \\
\hline & Sore & 35,8 & 89 \\
\hline \multirow{2}{*}{7} & Pagi & 34,9 & 91 \\
\hline & Sore & 31,5 & 81 \\
\hline \multirow{2}{*}{8} & Pagi & 34,6 & 86 \\
\hline & Sore & 33,3 & 92 \\
\hline \multirow{2}{*}{9} & Pagi & 35,4 & 77 \\
\hline & Sore & 32,6 & 81 \\
\hline
\end{tabular}

Total lamanya pengomposan untuk pengujian ini adalah 12 hari yaitu 3 hari fase meshophilik dan 9 hari fase thermophilik. Karakteristik kompos yang dihasilkan diperlihatkan pada tabel 4 .

Tabel 4 Kompos Hasil Pengujian 18 rpm

\begin{tabular}{lll}
\hline Parameter & $\begin{array}{l}\text { Pengujian } \\
18 \mathrm{rpm}\end{array}$ & $\begin{array}{l}\text { Standar } \\
\text { Permentan } \\
\text { tahun 2011 }\end{array}$ \\
\hline Warna & Hitam & \\
\hline Bau / tekstur & Tanah \\
\hline Massa awal & $40 \mathrm{~kg}$ \\
\hline Massa akhir & $5,2 \mathrm{~kg}$ \\
\hline $\mathrm{pH}$ & 7,76 & $4-9$ \\
\hline Karbon & $46,15 \%$ & Min 15\% \\
\hline Rasio C/N & 24,68 & $15-25$ \\
\hline Kadar air & $33,62 \%$ & $15-25 \%$ \\
\hline
\end{tabular}

Hasil pengujian jenis kedua yang dilakukan pada putaran drum $25 \mathrm{rpm}$ dan $30 \mathrm{rpm}$. pengujian 1 lamanya pengadukan adalah 2 menit sedangkan pada pengujian 2 lama pengadukan 7 menit

Setelah dilakukan pengujian, diperoleh hasil sebagai berikut: Lama proses pengomposan pengujian 1 yaitu pada putaran $25 \mathrm{rpm}$ adalah 14 hari (sudah termasuk fase meshophilik dan fase thermophilik), sedangkan lama proses pengomposan pengujian 2 yaitu pada putaran $30 \mathrm{rpm}$, adalah 11 hari (sudah termasuk fase meshophilik dan fase thermophilik). 
Data temperatur hasil pengujian 1 yaitu 25 rpm selama 2 menit dan pengujian 2 pada $30 \mathrm{rpm}$ selama 7 menit diperlihatkan pada gambar 5 .

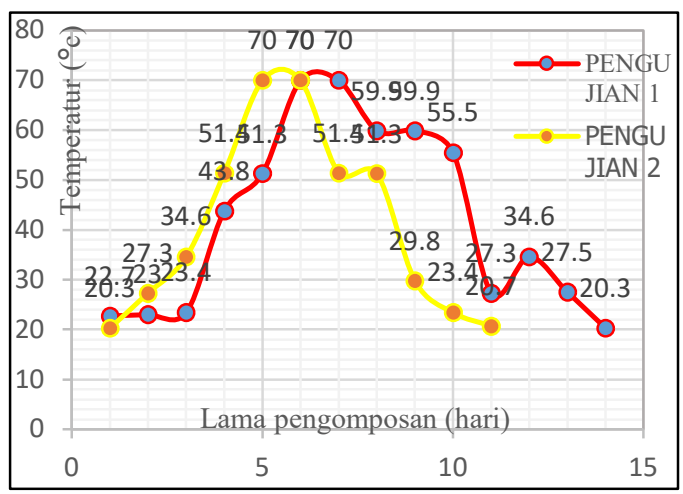

\section{Gambar 5 Grafik Temperatur}

Waktu pengomposan pada putaran $25 \mathrm{rpm}$ selama 2 menit yaitu 14 hari dan waktu proses pengomposan pada putaran $30 \mathrm{rpm}$ selama 7 menit adalah 11 hari.

Kenaikan temperatur menunjukan terjadi reaksi eksotermik atau timbulnya panas akibat pelepasan energi, menandakan munculnya mikroorganisme thermofhilik. Temperatur maksimum yang dicapai adalah $70^{\circ} \mathrm{C}$. Hal ini cukup baik karena jika Temperatur melebihi $70^{\circ} \mathrm{C}$ dapat mengakibatkan mikroorganisme di dalam sampah mati, sehingga proses pengomposan akan gagal.

Tahap aktif atau proses penguraian bakteri pada sampah terjadi pada hari ke 3 sampai hari ke 5, ditandai dengan naiknya temperatur $30^{\circ} \mathrm{C}-70^{\circ} \mathrm{C}$. Penurunan temperatur memperlihatkan proses pematangan kompos. Pada pengujian 1 proses pematangan dimulai pada hari ke 8 hingga hari ke 14, proses pematangan kompos terjadi selama 6 hari. Untuk pengujian kedua proses pematangan terjadi hanya 4 hari yaitu pada hari ke7 hingga hari ke 11 . Setelah kompos matang, maka kompos siap untuk digunakan.

Kelembaban minimum yang terjadi selama proses pengomposan adalah $67 \%$ sedangkan kelembaban maksimum 94\%. hal ini diperlihatkan pada grafik kelembaban pada gambar 6 . Kelembaban cenderung naik pada proses penguraian kompos dan cenderung turun setelah fase pematangan kompos.

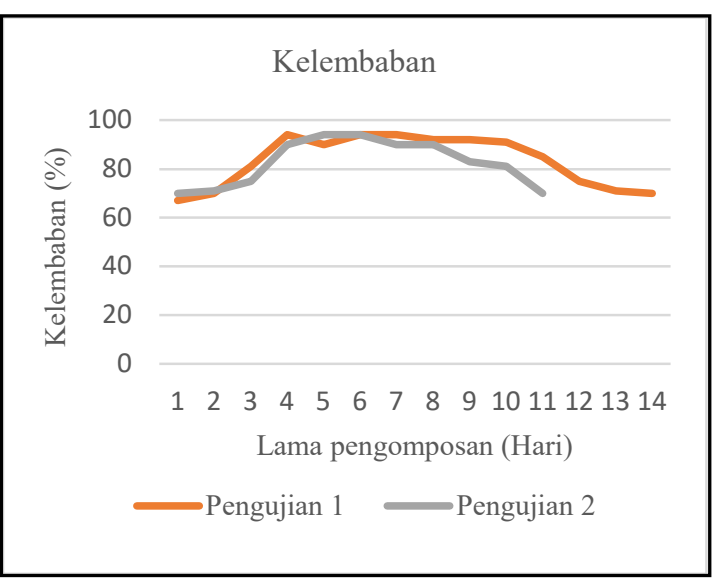

\section{Gambar 6 Grafik Kelembaban}

Karakteristik kompos yang dihasilkan menyerupai tanah, remah dan tidak berbau, seperti diperlihatkan pada Gambar 7.

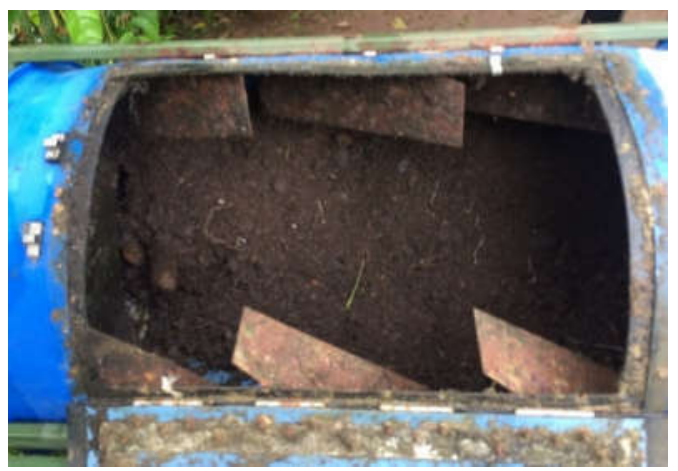

\section{Gambar 7 Kompos yang dihasilkan}

Berdasarkan hasil pengujian, karakteristik kompos yang dihasilkan sudah sesuai dengan karakteristik kompos yang baik yaitu berwarna kehitaman, tidak berbau busuk dan tekstur menyerupai tanah. Seperti diperlihatkan pada tabel 5 .

Tabel 5 Karakteristik Kompos

\begin{tabular}{lll}
\hline Parameter & $\begin{array}{l}\text { Pengujian } \\
\text { 25 RPM }\end{array}$ & $\begin{array}{l}\text { Pengujian } \\
\text { 30 RPM }\end{array}$ \\
\hline Warna & kehitaman & kehitaman \\
\hline Bau & Tidak berbau & Tidak berbau \\
\hline Tekstur & $\begin{array}{l}\text { Seperti } \\
\text { tanah }\end{array}$ & $\begin{array}{l}\text { Seperti } \\
\text { tanah }\end{array}$ \\
\hline $\begin{array}{l}\text { Massa } \\
\text { awal }\end{array}$ & $40 \mathrm{~kg}$ & $40 \mathrm{~kg}$ \\
\hline $\begin{array}{l}\text { Massa } \\
\text { akhir }\end{array}$ & $4,2 \mathrm{~kg}$ & $5,6 \mathrm{~kg}$ \\
\hline $\begin{array}{l}\text { Waktu } \\
\text { (hari) }\end{array}$ & 14 & 11 \\
\hline
\end{tabular}

12 Nugraha, Noviyanti, dkk; Pengujian Mesin Komposter Komunal Sampah Rumah Tangga Tipe Rotary Horizontal Kapasitas $40 \mathrm{Kg}$ 
Kandungan karbon didalam kompos (C) hasil pengujian 1 sesuai dengan standar SNI, tetapi hasil dari pengujian 2 sedikit diatas stardar SNI perbedaan nya yaitu sebesar 3\%. Seperti diperlihatkan pada tabel 6 .

Tabel 6 Kandungan Kompos

\begin{tabular}{lllll}
\hline \multirow{2}{*}{ Kandungan } & \multirow{2}{*}{$\begin{array}{l}\text { Uji } \\
\text { Uji }\end{array}$} & 2 & Standar & \\
\cline { 4 - 5 } $\mathrm{C}(\%)$ & 29,4 & 33,3 & Min 15 & $9,80-32$ \\
\hline $\begin{array}{l}\mathrm{N} \\
(\%)\end{array}$ & 1,7 & 1,02 & Min 0,4 & Min 0,4 \\
\hline $\mathrm{C} / \mathrm{N}$ & 17,6 & 32,6 & $15-25$ & $10-20$ \\
\hline $\mathrm{kdrAir}$ & 15,8 & 35,3 & $15-25$ & Maks 50 \\
$(\%)$ & 7 & 5,2 & $4-9$ & $6,80-7,49$ \\
\hline $\mathrm{PH}$ & 7 & & \\
\hline
\end{tabular}

Perbandingan kadar karbon dan nitrogen $(\mathrm{C} / \mathrm{N})$ untuk pengujian 1 sudah sesuai standar sedangkan untuk pengujian 2 masih diatas yang distandarkan yaitu 32,6 masih diatas 20 .

PH yang di hasilkan antara 5-7 sudah sesuai dengan standar permentan yaitu antara 4-9 dan standar SNI yaitu 6,8-7,49

\section{KESIMPULAN}

Waktu pengomposan pada pengujian jenis pertama yaitu pengadukan pada putaran $18 \mathrm{rpm}$ dengan lama proses pengadukan 15 menit dan dua kali proses pengadukan dalam sehari adalah 12 hari. Waktu pengomposan pada pengujian jenis kedua untuk melihat pengaruh putaran rpm, yaitu pengujian 1 pada putaran $25 \mathrm{rpm}$ selama dua menit adalah 14 hari. Waktu pengomposan pengujian 2 pada putaran $30 \mathrm{rpm}$ selama 7 menit adalah 11 hari.

Lamanya proses pengomposan dari semua pengujian sesuai target yaitu tidak lebih dari 14 hari.

Penggunaan komposter mempercepat proses pengomposan dari biasanya sekitar 5 sampai 8 minggu menjadi 2 minggu.

Pengaruh variasi putaran (rpm) belum terlihat pengaruh yang signifikan terhadap lamanya proses pengomposan, hal ini berdasarkan data untuk putaran $18 \mathrm{rpm}$ lama pengomposan 12 hari, untuk putaran $25 \mathrm{rpm}$ lama pengomposan 14 hari dan untuk putaran $35 \mathrm{rpm}$ lama pengomposan adalah 11 hari.

Karakteristik kompos yang dihasilkan sudah sesuai dengan karakteristik kompos yang baik yaitu berwarna kehitaman, tidak berbau busuk dan tekstur menyerupai tanah. Perbandingan kadar karbon dan nitrogen $(\mathrm{C} / \mathrm{N})$ dan kadar karbon $(\mathrm{C})$ sudah sesuai standar tetapi untuk pengujian 2 masih diatas yang distandarkan. Tetapi perbedaan nya tidak terlalu signifikan yaitu dan 3\% diatas standar SNI.

$\mathrm{PH}$ kompos yang dihasilkan, Kadar air dan kadar Nitrogen sudah sesuai dengan standar Permentan dan standar SNI.

\section{SARAN}

Dilakukan lagi pengujian dengan rpm yang lebih bervariasi tetapi waktu pemutaran nya tetap misal 5 menit, untuk melihat pengaruh kecepatan putaran.

Dilakukan pengujian pada variabel kecepatan putar yang tetap tetapi lama pengadukan nya bervariasi, untuk melihat pengaruh lamanya proses pengadukan terhadap lamanya proses pengomposan.

\section{DAFTAR PUSTAKA}

[1] Taqim. Nursiwan. 2007. Panduan Mengelola Sampah. Buku Kementrian Lingkungan Hidup: Pekanbaru

[2] Tahir, I. 2008. Pembuatan Kompos. Diktat Kuliah Universitas Gajah Mada. Jogjakarta: Universitas Gajah Mada

[3] Damanhuri. E, Padmi. Tri. 2010. Pengelolaan Sampah. Diktat Kuliah Teknik Lingkungan: ITB.

[4] Nugraha. N, Fauzi. O, dkk. 2017. Rancang Bagun Komposter Rumah Tangga Komunal Sebagai Solusi Pengolahan Sampah Mandiri Kelurahan Pasirjati Bandung. CR journal

[5] Nugraha. N, Fauzi. O, Mahardika. A, Dkk. 2017. Modifikasi Dan Pembuatan Mesin Komposter Komunal Horizontal Kapasitas 40kg. Seminar Nasional Rekayasa Aplikasi Teknik Mesin Di Industri: Itenas.

[6] Setyorini. D, dkk. 2006. Pupuk Hayati Pupuk Organik. Buku Balitanah Litbang Pertanian. 